\title{
Persepsi Mahasiswa Atas Galeri Investasi Perguruan Tinggi dan Pengaruhnya Terhadap Minat Berinvestasi
}

\author{
Aang Munawar ${ }^{1}$ Rini Syarif ${ }^{2}$ Morita $^{3}$ \\ DOI: https://doi.org/10.36339/jaspt.v3i2.277
}

\section{Abstract}

The purpose of this study was to identify student perceptions about the College Investment Gallery. The analysis continues by measuring the effect of students' perceptions on investment interest. This research was conducted in May-July 2019 of 200 students who were members of the STIE Kesatuan Bogor Investment Gallery. The results showed that the STIE Kesatuan Investment Gallery is strongly perceived as a Good Investment Gallery and meets the expectations of students. Student Perception significantly influences Investment Interest.

Keywords: students' perception, investment interest, investment gallery

\begin{abstract}
Abstrak
Tujuan penelitian ini adalah untuk mengidentifikasi persepsi mahasiswa tentang Galeri Investasi Perguruan Tinggi. Analisis dilanjutkan dengan mengukur pengaruh persepsi mahasiswa terhadap minat berinvestasi. Penelitian ini dilakukan pada Mei-Juli 2019 terhadap 200 orang Mahasiswa Anggota Galeri Investasi STIE Kesatuan Bogor. Hasil penelitian menunjukkan bahwa Galeri Investasi STIE Kesatuan dipersepsikan kuat sebagai Galeri Investasi yang Baik dan memenuhi ekspektasi para mahasiswa. Persepsi Mahasiswa berpengaruh secara nyata terhadap Minat Berinvestasi.
\end{abstract}

Kata Kunci: persepsi mahasiswa, minat berinvestasi, galeri investasi

1. Program Studi Manajemen Institut Bisnis dan Informatika Kesatuan

Program Studi Perbankan dan Keuangan IBI Kesatuan

Program Studi Manajemen Pemasaran Sekolah Tinggi IImu Ekonomi Kesatuan, Jalan Ranggagading №. 1 Bogor Indonesia 16123

EMail aang.munawar@ibik.ac.id

Submitted: Desember 2019

Accepted: Desember 2019

\section{PENDAHULUAN}

Investasi di Pasar Modal telah menjadi bagian tak terpisahkan dengan program pendidikan dan pengajaran di Perguruan Tinggi. Berbagai kemudahan berinvestasi di Pasar Modal telah diciptakan, salah satunya dengan mendirikan Galeri Investasi sebagai bentuk kerjasama antara Bursa Efek Indonesia dengan Perguruan Tinggi. Galeri Investasi ini pun memiliki peranan diperluas, yang tidak hanya memberikan pelayanan kepada para mahasiswa, namun bagi masyarakat yang hendak berinvestasi di pasar modal pun dapat melakukannya melalui Galeri Investasi milik Perguruan Tinggi tersebut.

Galeri Investasi Perguruan Tinggi, menerapkan konsep 3 in 1 yang merupakan kerjasama antara BEl, Perguruan Tinggi dan Perusahaan Sekuritas. Sampai saat ini,
JAS-PT

JURNAL ANALISIS SISTEM PENDIDIKAN TINGG

ISSN 2580 - 5339

elSSN $2620-5718$

Volume 3

Nomor 2

DESEMBER 2019

Hal $89-96$

FORUM DOSEN INDONESIA 
terdapat 413 Galeri investasi yang tersebar di seluruh wilayah Indonesia. Galeri Investasi yang berafiliasi ke BEI Jakarta (Pusat) berjumlah 40 Lokasi. (Tabel 1).

Tabel 1 Lokasi Galeri Investasi di Wilayah Jakarta

\begin{tabular}{|c|c|c|}
\hline No & Nama Perguruan Tinggi & Mitra \\
\hline 1 & Perbanas Institute & PT MNC Sekuritas \\
\hline 2 & IPMI International Business School & PT Kresna Sekuritas \\
\hline 3 & Kalbis Institute & PT MNC Sekuritas \\
\hline 4 & Politeknik Negeri Jakarta & PT MNC Sekuritas \\
\hline 5 & President University & PT Reliance Sekuritas Indonesia Tbk. \\
\hline 6 & Sampoerna University & PT NISP Sekuritas \\
\hline 7 & STEI Jakarta & PT MNC Sekuritas \\
\hline 8 & STEIN Kalimalang & PT MNC Sekuritas \\
\hline 9 & STIE Indonesia Banking School & PT Mandiri Sekuritas \\
\hline 10 & STIE Pelita Bangsa & PT MNC Sekuritas \\
\hline 11 & STIE Tri Bhakti Bekasi & PT Indo Premier Sekuritas \\
\hline 12 & STIE Trisakti (Trisakti School Of Management) & PT Mirae Asset Sekuritas Indonesia \\
\hline 13 & STMIK ESQ (ESQ Business School) & PT Indo Premier Sekuritas \\
\hline 14 & Universitas Al Azhar & PT MNC Sekuritas \\
\hline 15 & Universitas Bakrie & PT OSO Sekuritas \\
\hline 16 & Universitas Bunda Mulia & PT MNC Sekuritas \\
\hline 17 & Universitas Darma Persada & PT MNC Sekuritas \\
\hline 18 & Universitas Gunadarma & PT Valbury Asia Sekuritas \\
\hline 19 & Universitas Krisnadwipayana & PT MNC Sekuritas \\
\hline 20 & Universitas Kristen Krida Wacana (UKRIDA) & PT Kresna Sekuritas \\
\hline 21 & Universitas Mercu Buana & PT MNC Sekuritas \\
\hline 22 & Universitas MH Thamrin (Kampus AKA) & PT Mandiri Sekuritas \\
\hline 23 & Universitas Nasional & PT Profindo Sekuritas Indonesia \\
\hline 24 & Universitas Pancasila & Dalam Proses penggantian AB \\
\hline 25 & Universitas Tarumanagara & PT Sucor Sekuritas \\
\hline 26 & Universitas Trisakti & PT Danareksa Sekuritas \\
\hline 27 & UPN Veteran & PT MNC Sekuritas \\
\hline 28 & Universitas Muhammadiyah Prof. Dr. HAMKA & PT MNC Sekuritas \\
\hline 29 & Universitas Respati Indonesia & PT Pacific 2000 Sekuritas \\
\hline 30 & Universitas MH Thamrin (Kampus A) & PT OSO Sekuritas \\
\hline 31 & Univeritas Kristen Indonesia & PT Kresna Sekuritas \\
\hline 32 & Universitas Pertamina & PT Kresna Sekuritas \\
\hline 33 & STEI TAZKIA Bogor & PT MNC Sekuritas \\
\hline 34 & STIE Kesatuan Bogor & PT MNC Sekuritas \\
\hline 35 & Institut Pertanian Bogor & PT MNC Sekuritas \\
\hline 36 & STEBI Global Mulia Cikarang & PT MNC Sekuritas \\
\hline 37 & Kopi Tjoean & PT Phillip Sekuritas Indonesia \\
\hline 38 & Pasar Ranggagading & PT MNC Sekuritas \\
\hline 39 & Universitas Pakuan & PT Mandiri Sekuritas \\
\hline 40 & Vokasi Universitas Indonesia & PT Indo Premier Sekuritas \\
\hline
\end{tabular}

\section{Sumber: www.idx.co.id Maret 2019}

Bagi mahasiswa, untuk berinvestasi di Pasar Modal relatif akan banyak pertimbangan yang dilakukannya. Salah satunya adalah ketersediaan dana. Hal ini sudah diantisipasi oleh Bursa Efek Indonesia, dengan memberikan keringanan besaran dana awal untuk bertransaksi di pasar modal. Cukup dengan dana Rp 100.000,- mahasiswa sudah

JAS-PT

JURNAL ANALSIS SISTEM PENDIDIKAN TINGG ISSN 2580 - 5339 eISSN 2620 - 5718

Volume 3

Nomor 2

DESEMBER 2019

Hal $89-96$

FORUM DOSEN INDONESIA memperoleh akun yang dapat dipergunakan untuk bertransaksi di Pasar Modal melalui Galeri Investasi Perguruan Tinggi.

Namun demikian, mahasiswa seringkali memperhatikan secara fisik kondisi Galeri Investasi dimaksud. Layanan personil Galeri Investasi pun tidak luput dari pertimbangan para mahasiswa. Semua hal yang nampak dan dialami mahasiswa membangun persepsi tentang sesuatu hal.

Mulyana (2010), mengemukakan beberapa prinsip persepsi sebagai berikut: 
1. Persepsi berdasarkan pengamatan yaitu persepsi manusia terhadap seseorang, obyek atau kejadian dan reaksi mereka terhadap hal-hal itu berdasarkan pengalaman dan pembelajaran masa lalu mereka berkaitan dengan orang, benda dan kejadian serupa.

2. Persepsi bersifat selektif, yaitu setiap manusia sering mendapat rangsangan indrawi sekaligus, untuk itu perlu selektif dari rangsangan yang penting, karenanya atensi suatu rangsangan merupakan faktor utama menentukan selektifitas kita atas rangsangan tersebut.

3. Persepsi bersifat dugaan, yaitu persepsi bersifat dugaan terjadi oleh karena data yang diperoleh mengenai obyek lewat penginderaan tidak pernah lengkap. Persepsi merupakan loncatan langsung pada kesimpulan.

4. Persepsi bersifat evaluatif, yaitu persepsi persifat evaluatif maksudnya adalah kadangkala orang menafsirkan pesan sebagai suatu proses kebenaran, akan tetapi terkadang alat indera dan persepsi kita menipu kita, sehingga kita juga ragu seberapa dekat persepsi kita denga realitas yang sebenarnya. Untuk itu dalam mencapai suatu tingkat kebenaran perlu evaluasi-evaluasi yang seksama.

5. Persepsi bersifat kontekstual, yaitu persepsi bersifat kontekstual mnerupakan pengaruh paling kuat dalam mempersepsi suatu obyek. Konteks yang melingkungi kita ketika melihat seseorang, suatu obyek atau suatu kejadian sangat mempengaruhi struktur kognitif, pengharapan prinsip yaitu: kemiripan atau kedekatan dan kelengkapan dan kecenderung mempersepsi suatu rangsangan atau kejadian yang terdiri dari struktur dan latar belakangnya

Rumusan Masalah penelitian ini adalah Bagaimana Persepsi Mahasiswa atas Galeri Investasi STIE Kesatuan Bogor dan bagaimana pengaruhnya terhadap minat mahasiswa berinvestasi di Galeri Investasi.

\section{METODOLOGI PENELITIAN}

Penelitian dilakukan di Galeri Investasi STIE Kesatuan pada Mei-Juli 2019 terhadap 200 orang mahasiswa. Populasi penelitian ini adalah mahasiswa Program Studi Akuntansi dan Manajemen Keuangan STIE Kesatuan. Analisis data dilakukan dengan analisis deskriptif dan regresi berganda.

Sebaran responden sebagaimana terlihat pada Tabel 2. Mayoritas Responden berjenis kelamin wanita (68\%) dan $32 \%$ merupakan responden berjenis kelamin laki-laki. Data Usia responden tersebar antara 18 tahun sampai dengan 26 tahun. Responden berusia 20 tahun sebanyak $46 \%$ dan $31 \%$ responden berusia 19 tahun, sisanya tersebar pada tingkat usia lain. Responden berasal dari sembilan kelas yang berbeda (kelas reguler dan kelas karyawan/ekstensi). Mayoritas responden merupakan mahasiswa kelas reguler. 59,5\% responden adalah mahasiswa program studi Akuntansi - S1, 40,5\% merupakan mahasiswa program studi Manajemen Keuangan - S1.

\section{HASIL DAN PEMBAHASAN}

Untuk mengukur tingkat Persepsi Mahasiswa secara berkelompok, akan ditampilkan dan diuraikan rekapitulasi distribusi frekuensi jawaban 200 orang responden dengan menggunakan skor skala likert. Untuk kemudian berdasarkan skor tersebut, dilakukan kategorisasi interpretasi. Riduwan (2007) memberi kategorisasi interpretasi skor menjadi lima tingkat sebagaimana tercantum pada tabel 3.

JAS-PT

JURNAL ANALISIS SISTEM PENDIDIKAN TINGG ISSN $2580-5339$ eISSN $2620-5718$ Volume 3 Nomor 2 DESEMBER 2019 Hal $89-96$ 
Tabel 2 Distribusi Frekuensi Responden Berdasarkan Karakteristik

\begin{tabular}{llcc}
\hline & Karakteristik Responden & Frekuensi & Prosentase \\
\hline Jenis Kelamin & Laki-laki & 64 & $32.0 \%$ \\
Usia & Wanita & 136 & $68.0 \%$ \\
& 18 tahun & 2 & $1,0 \%$ \\
& 19 tahun & 62 & $31,0 \%$ \\
& 20 tahun & 92 & $46,0 \%$ \\
& 21 tahun & 29 & $14,5 \%$ \\
& 22 tahun & 5 & $2,5 \%$ \\
& 23 tahun & 7 & $3,5 \%$ \\
& 24 tahun & 1 & $0,5 \%$ \\
Kelas & 25 tahun & 1 & $0,5 \%$ \\
& 26 tahun & 1 & $0,5 \%$ \\
& 4 MK A P & 25 & $12,5 \%$ \\
& 4 MK B P & 9 & $4,5 \%$ \\
& 4 MK C P & 11 & $5,5 \%$ \\
& 4 MK D P & 11 & $5,5 \%$ \\
& 4 MK A K & 25 & $12,5 \%$ \\
Semester & 4 AK A P & 38 & $19,0 \%$ \\
Program Studi & 4 AK B P & 25 & $12,5 \%$ \\
& 4 AK C P & 29 & $14,5 \%$ \\
& 4 AK D P & 27 & $13,5 \%$ \\
& 4 & 199 & $99.5 \%$ \\
& 6 & 1 & $0.5 \%$ \\
& Manajemen Keuangan - S1 & 81 & $40.5 \%$ \\
& Akuntansi - S1 & 119 & $59.5 \%$ \\
\hline
\end{tabular}

Sumber: Data Primer Diolah, 2019

Tabel 3. Kategorisasi Interpretasi Skor

Nilai Skor

Angka 0\% - 20\%

Angka 21\% - 40\%

Angka $41 \%-60 \%$

Angka $61 \%-80 \%$

Angka $81 \%-100 \%$
Kriteria Interpretasi Skor

Sangat Lemah

Lemah

Cukup

Kuat

Sangat Kuat

Sumber: Riduwan (2007)

\section{Persepsi Mahasiswa Tentang Galeri Investasi STIE Kesatuan}

Hal pertama yang dianalisis adalah persepsi mahasiswa tentang Tampilan Galeri Investasi. Hal ini biasanya menjadi poin penting utama sebelum seseorang beraktivitas atau bertransaksi. Seseorang akan bertransaksi setelah memiliki keyakinan akan tempatnya terutama dari aspek tampilan.

Tabel 4 menunjukan bahwa mayoritas responden menjawab baik (55,5\%) tentang

JAS-PT

JURNAL ANALISIS SISTEM PENDIDIKAN TINGGI

ISSN $2580-5339$

elSSN $2620-5718$

Volume 3

Nomor 2

DESEMBER 2019

Hal $89-96$

Tampilan Galeri Investasi STIE Kesatuan. Sebagian responden lain menjawab sangat baik $(9 \%)$, sedangkan sisanya menjawab biasa $(37,5 \%)$ dan buruk $(0.5 \%)$. Diperoleh skor skala likert sebesar 0,732 atau $73,2 \%$. Hal ini dapat diartikan bahwa persepsi responden tentang Tampilan Galeri Investasi adalah kuat.

FORUM DOSEN INDONESIA 
Tabel 4 Distribusi Frekuensi Jawaban Responden Tentang Tampilan Galeri Investasi

\begin{tabular}{lcccc}
\hline \multicolumn{1}{c}{ Jawaban } & Frekuensi & Prosentase & Bobot & Jumlah Skor \\
\hline Sangat Buruk & 0 & $0.0 \%$ & 1 & 0 \\
Buruk & 1 & $0.5 \%$ & 2 & 2 \\
Biasa & 75 & $37.5 \%$ & 3 & 225 \\
Baik & 115 & $57.5 \%$ & 4 & 460 \\
Sangat Baik & 9 & $4.5 \%$ & 5 & 45 \\
Total & 200 & $100 \%$ & & 732 \\
\hline \multicolumn{5}{c}{ Skor Skala Likert: $732 /(5 \times 200)=$} \\
\hline
\end{tabular}

Sumber: Data Primer Diolah, 2019

Tabel 5 Distribusi Frekuensi Jawaban Responden Tentang Kemudahan Menjumpai Galeri Investasi

\begin{tabular}{lcccc}
\hline \multicolumn{1}{c}{ Jawaban } & Frekuensi & Prosentase & Bobot & Jumlah Skor \\
\hline Sangat Tidak Mudah & 0 & $0.0 \%$ & 1 & 0 \\
Tidak Mudah & 1 & $0.5 \%$ & 2 & 2 \\
Biasa & 36 & $18.0 \%$ & 3 & 108 \\
Mudah & 124 & $62.0 \%$ & 4 & 496 \\
Sangat Mudah & 39 & $19.5 \%$ & 5 & 195 \\
Total & 200 & $100 \%$ & & 801 \\
\hline \multicolumn{4}{c}{ Skor Skala Likert: $801 /(5 \times 200)=$} \\
\hline
\end{tabular}

Sumber: Data Primer Diolah, 2019

Pada Tabel 5 menampilkan data bahwa mayoritas responden menjawab Mudah (62\%) tentang Kemudahan Menjumpai Galeri Investasi STIE Kesatuan. Sebagian responden lain bahkan menjawab sangat mudah $(19,5 \%)$. Lainnya menjawab biasa $(18 \%)$ dan Tidak Mudah (0.5\%). Diperoleh skor skala likert sebesar 0,801 atau 80,1\%. Hal ini dapat diartikan bahwa responden bersepakat untuk berpersepsi sangat kuat tentang Kemudahan Menjumpai Galeri Investasi.

Tabel 6 Distribusi Frekuensi Jawaban Responden Tentang Kelengkapan Sarana Galeri Investasi

\begin{tabular}{lcccc}
\hline \multicolumn{1}{c}{ Jawaban } & Frekuensi & Prosentase & Bobot & Jumlah Skor \\
\hline Sangat Tidak Lengkap & 0 & $0.0 \%$ & 1 & 0 \\
Tidak Lengkap & 13 & $6.5 \%$ & 2 & 26 \\
Biasa & 77 & $38.5 \%$ & 3 & 231 \\
Lengkap & 100 & $50.0 \%$ & 4 & 400 \\
Sangat Lengkap & 10 & $5.0 \%$ & 5 & 50 \\
Total & 200 & $100 \%$ & & 707 \\
\hline \multicolumn{4}{c}{ Skor Skala Likert: $707 /(5 \times 200)=$} \\
\hline
\end{tabular}

Sumber: Data Primer Diolah, 2019

Galeri Investasi STIE Kesatuan dipersepsikan lengkap sarananya oleh 50\% responden (Lihat Tabel 6). 5\% responden menyatakan sangat lengkap, 38\% responden lainnya menyatakan biasa dan tidak lengkap sebanyak $13 \%$ responden. Diperoleh skor skala likert sebesar 0,707 atau 70,7\%. Hal ini dapat diartikan bahwa kelengkapan sarana Galeri Investasi dipersepsikan kuat oleh mayoritas responden.

Pada Tabel 7 ditampilkan skor skala likert sebesar 0,749 atau $74,9 \%$. Skor tersebut diperoleh dari perhitungan jawaban responden yang menyatakan mudah $(58,5 \%)$, sangat mudah $(9,5 \%)$, biasa $(29 \%)$ dan biasa $(3 \%)$ saat diminta persepsinya tentang kemudahan bertransaksi di Galeri Investasi STIE Kesatuan. Hal ini dapat diartikan

JAS-PT

JURNAL ANALISIS SISTEM PENDIDIKAN TINGG ISSN $2580-5339$ elSSN $2620-5718$ Volume 3 Nomor 2 DESEMBER 2019 Hal $89-96$

FORUM DOSEN INDONESIA 
bahwa kemudahan bertransaksi di Galeri Investasi dipersepsikan kuat oleh mayoritas responden.

Tabel 7 Distribusi Frekuensi Jawaban Responden Tentang Kemudahan Bertransaksi di Galeri Investasi

\begin{tabular}{lcccc}
\hline \multicolumn{1}{c}{ Jawaban } & Frekuensi & Prosentase & Bobot & Jumlah Skor \\
\hline Sangat Tidak Mudah & 0 & $0.0 \%$ & 1 & 0 \\
Tidak Mudah & 6 & $3.0 \%$ & 2 & 12 \\
Biasa & 58 & $29.0 \%$ & 3 & 174 \\
Mudah & 117 & $58.5 \%$ & 4 & 468 \\
Sangat Mudah & 19 & $9.5 \%$ & 5 & 95 \\
Total & 200 & $100 \%$ & & 749 \\
\hline \multicolumn{4}{c}{ Skor Skala Likert: $749 /(5 \times 200)=$} \\
\hline
\end{tabular}

Sumber: Data Primer Diolah, 2019

Tabel 8 Distribusi Frekuensi Jawaban Responden Tentang Kemudahan Memperoleh Informasi Investasi Melalui Galeri Investasi

\begin{tabular}{lcccc}
\hline \multicolumn{1}{c}{ Jawaban } & Frekuensi & Prosentase & Bobot & Jumlah Skor \\
\hline Sangat Tidak Mudah & 0 & $0.0 \%$ & 1 & 0 \\
Tidak Mudah & 4 & $2.0 \%$ & 2 & 8 \\
Biasa & 49 & $24.5 \%$ & 3 & 147 \\
Mudah & 134 & $67.0 \%$ & 4 & 536 \\
Sangat Mudah & 13 & $6.5 \%$ & 5 & 65 \\
Total & 200 & $100 \%$ & & 756 \\
\hline \multicolumn{5}{c}{ Skor Skala Likert: $756 /(5 \times 200)=$} \\
\hline
\end{tabular}

Sumber: Data Primer Diolah, 2019

Tabel 8 menampilkan skor skala likert sebesar 0,756 atau 75,6\%. Skor tersebut diperoleh dari kalkulasi jawaban responden yang mayoritas menyatakan mudah $(67 \%)$, sangat mudah $(6,5 \%)$, biasa $(24,5 \%)$ dan tidak mudah $(2 \%)$ saat ditanya tentang kemudahan memperoleh informasi investasi melalui Galeri Investasi. Dengan demikian dapat diartikan bahwa responden berpersepsi kuat tentang kemudahan memperoleh informasi investasi melalui Galeri Investasi. Persepsi responden belum mencapai tingkat sangat kuat tentang hal ini. Masih terdapat responden yang memberi respon tidak mudah dan biasa saja.

Tabel 9 Distribusi Frekuensi Jawaban Responden Tentang Kemudahan Menemukan Kontak Person Galeri Investasi Saat Membutuhkan Informasi

\begin{tabular}{lcccc}
\hline \multicolumn{1}{c}{ Jawaban } & Frekuensi & Prosentase & Bobot & Jumlah Skor \\
\hline Sangat Tidak Mudah & 0 & $0.0 \%$ & 1 & 0 \\
Tidak Mudah & 5 & $2.5 \%$ & 2 & 10 \\
Biasa & 44 & $22.0 \%$ & 3 & 132 \\
Mudah & 130 & $65.0 \%$ & 4 & 520 \\
Sangat Mudah & 21 & $10.5 \%$ & 5 & 105 \\
Total & 200 & $100 \%$ & & 767 \\
\hline \multicolumn{4}{c}{ Skor Skala Likert: $767 /(5 \times 200)=$} \\
\hline
\end{tabular}

JAS-PT

JURNAL ANALISIS SISTEM PENDIDIKAN TINGGI

ISSN $2580-5339$

eISSN $2620-5718$

Volume 3

Nomor 2

DESEMBER 2019

Hal $89-96$

FORUM DOSEN INDONESIA
Sumber: Data Primer Diolah, 2019

Dalam Tabel 9 terlihat bahwa mayoritas responden menjawab mudah (65\%) dan sangat mudah $(10,5 \%)$ saat diminta persepsi tentang kemudahan menemukan kontak person Galeri Investasi saat membutuhkan informasi. Sisanya responden menjawab tidak mudah sebanyak $2.5 \%$ responden dan menjawab biasa sebanyak $22 \%$ 
responden. Diperoleh skor skala likert sebesar 0,767 atau 76,7\%. Dengan demikian dapat diartikan bahwa responden berpersepsi kuat tentang kemudahan menemukan Kontak Person Galeri Investasi saat membutuhkan informasi.

Tabel 10 Distribusi Frekuensi Jawaban Responden Tentang Tanggapan Petugas Galeri Investasi Atas Pertanyaan Yang Diajukan

\begin{tabular}{lcccc}
\hline \multicolumn{1}{c}{ Jawaban } & Frekuensi & Prosentase & Bobot & Jumlah Skor \\
\hline Sangat Buruk & 1 & $0.5 \%$ & 1 & 1 \\
Buruk & 1 & $0.5 \%$ & 2 & 2 \\
Biasa & 33 & $16.5 \%$ & 3 & 99 \\
Baik & 133 & $66.5 \%$ & 4 & 532 \\
Sangat Baik & 32 & $16.0 \%$ & 5 & 160 \\
Total & 200 & $100 \%$ & & 794 \\
\hline \multicolumn{5}{c}{ Skor Skala Likert: $794 /(5 \times 200)=$} \\
\hline
\end{tabular}

Sumber: Data Primer Diolah, 2019

Dalam Tabel 10 disajikan jawaban responden tentang tanggapan petugas Galeri Investasi atas pertanyaan yang diajukan. Terdapat $0,5 \%$ responden yang menjawab sangat buruk dan 0,5\% responden menjawab buruk. Walaupun demikian mayoritas responden menjawab baik $(66,5 \%)$ dan sangat baik sebanyak $16 \%$ responden. Sisanya menjawab biasa sebanyak $16,5 \%$ responden. Diperoleh skor skala likert sebesar 0,794 atau $79,4 \%$. Dengan demikian dapat diartikan bahwa responden berpersepsi kuat tentang tanggapan petugas Galeri Investasi atas pertanyaan yang diajukan. Atas jawaban responden yang berpersepsi sangat buruk dan buruk harus menjadi bahan evaluasi bagi Galeri Investasi STIE Kesatuan untuk dilakukannya perbaikan dan peningkatan kualitas pelayanan.

\section{Pengaruh Persepsi Mahasiswa Terhadap Minat Berinvestasi di Galeri Investasi}

Analisis selanjutnya adalah menganalisis pengaruh persepsi mahasiswa terhadap minat berinvestasi melalui Galeri Investasi.

Tabel 11. Hasil Analisis Regresi Persepsi Mahasiswa dan Minat Berinvestasi

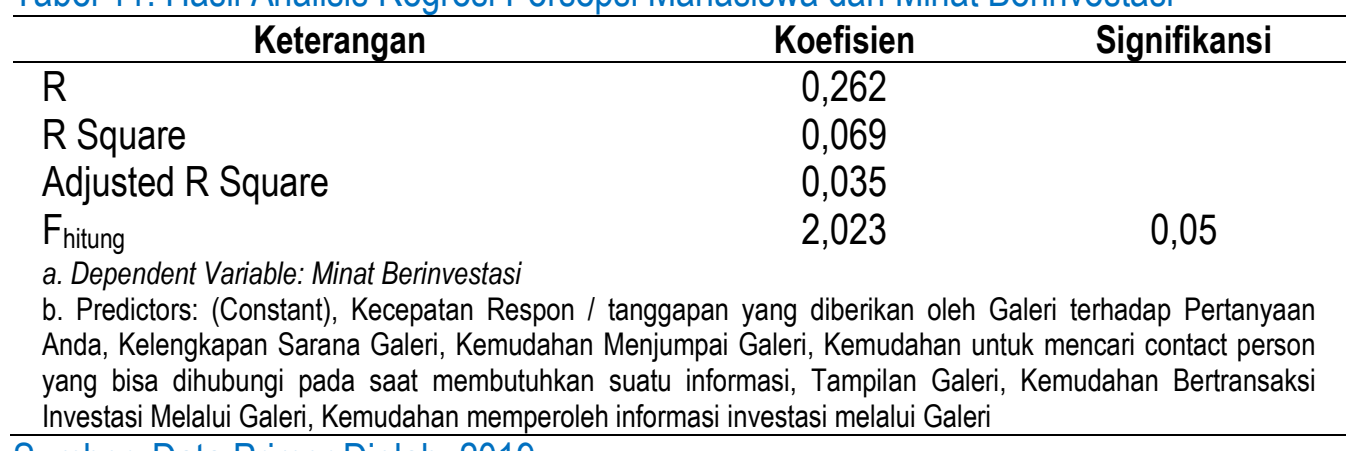

Sumber: Data Primer Diolah, 2019

Berdasarkan hasil analisis regresi sebagaimana tercantum pada Tabel 11, diperoleh Nilai $R$ (Regression) sebesar 0,262. Hal ini menunjukkan bahwa persepsi mahasiswa berpengaruh positif sebesar 0,262 terhadap minat berinvestasi. Tujuh faktor persepsi mahasiswa secara simultan dan signifikan mempengaruhi minat berinvestasi di Galeri Investasi. Hal ini dibuktikan dengan nilai F-Hitung sebesar 2,023 dan nilai signifikansi sebesar 0,05.

Nilai $R$ Square sebesar 0,069 dan Adjusted R Square sebesar 0,035 menunjukkan bahwa variabilitas Minat Berinvestasi para Mahasiswa STIE Kesatuan di Galeri Investasi mampu dijelaskan secara bersama-sama sebesar $6,9 \%$ oleh variabel

JAS-PT

JURNAL ANALISIS SISTEM PENDIDIKAN TINGGI ISSN $2580-5339$ elSSN $2620-5718$

Volume 3

Nomor 2

DESEMBER 2019

Hal 89 - 96 
persepsi mahasiswa. Sisanya $93,1 \%$ dipengaruhi faktor lain yang tidak masuk dalam model penelitian ini.

\section{PENUTUP}

Beberapa simpulan penelitian ini adalah sebagai berikut :

1. Galeri Investasi STIE Kesatuan dipersepsikan kuat memiliki tampilan yang baik, dipersepsikan sangat kuat dalam kemudahan dijumpai, dipersepsikan kuat sebagai Galeri Investasi yang memiliki kelengkapan sarana, dipersepsikan kuat dalam kemudahan bertransaksi, dipersepsikan kuat dalam kemudahan memperoleh informasi investasi melalui Galeri Investasi, dipersepsikan kuat memiliki kontak person yang mudah dihubungi saat reponden membutuhkan informasi, dan dipersepsikan kuat sebagai galeri investasi yang sangat baik dalam hal tanggapan petugas atas pertanyaan yang diajukan.

2. Tujuh Faktor Persepsi Mahasiswa secara bersama-sama (serentak) berpengaruh positif dan signifikan terhadap Minat Berinvestasi para Mahasiswa di Galeri Investasi.

\section{DAFTAR PUSTAKA}

Darmadji T., dan Fakhruddin, H. M. (2015). Pasar Modal di Indonesia. Jakarta: Salemba Empat.

Effendy, M., Surya, T.M. and Mubarak, M.M., 2009. Pengaruh Struktur Modal Terhadap Resiko Keuangan Perusahaan. Jurnal IImiah Kesatuan (JIK), 11(1).

Komang Luh, I Putu Mega. (2015). Kemampuan Pelatihan Pasar Modal Memoderasi Pengaruh Pengetahuan Investasi Dan Penghasilan Pada Minat Berinvestasi Mahasiswa. Jurnal IImiah Akuntansi dan Bisnis, Vol. 10, No. 2, Juli 2015.

Halim, Abdul. (2015). Analisis Investasi di Aset Keuangan. Jakarta: Penerbit Salemba Empat

Hermanto. (2017). Perilaku Mahasiswa Ekonomi di Universitas Esa Unggul Dalam Melakukan Investasi Di Pasar Modal. Jurnal Ekonomi, Volume 8, Nomor 2, Mei 2017.

Mulyana, Deddy. 2010. IImu Komunikasi : Suatu Pengantar. Bandung: PT. Remaja Rosdakarya

Mulyana, M., Hidayat, L. and Puspitasari, R., 2019. Mengukur Pengetahuan Investasi Para Mahasiswa Untuk Pengembangan Galeri Investasi Perguruan Tinggi. JAS-PT Jurnal Analisis Sistem Pendidikan Tinggi, 3(1), pp.31-52.

Purba, J. H. V., et. al (2019). Prediction Model in Medical Science and Health Care. International Journal of Engineering and Advanced Technology, 8(6S3), pp.815-818.

Riduwan 2007.Skala Pengukuran Variabel-variabel Penelitian. Bandung: Afabeth.

Situmorang, M., Andreas, \& Natariasari, R. (2014). Pengaruh Motivasi Terhadap Minat Berinvestasi Di Pasar Modal Dengan Pemahaman Investasi Dan Usia

JAS-PT

ISSN $2580-5339$ eISSN $2620-5718$

Volume 3

Nomor 2

DESEMBER 2019

Hal 89 - 96 Sebagai Variabel Moderat. JOM FEKON, 1.

Sugianto, D. (2017). Investor Aktif Pasar Modal Kini Didominasi Anak Muda. https://finance.detik.com/bursa-dan-valas/d-3426387/investor-aktif-pasarmodal-kini-didominasi-anak-muda (diakses pada 26 Agustus 2019 13:05 WIB) 